\title{
Chromosomal Foetal and Placenta Abnormalities Associated with Exomphalos and Umbicinal Hernia
}

\author{
Drikos Ioannis* \\ Pediatric Clinic, General Hospital of Elefsina, Greece
}

Submission: November 24, 2016; Published: February 08, 2017

*Corresponding author: Ioannis Drikos, Pediatric Clinic, General Hospital of Elefsina, Thiassio, Hellas, Gennimatas Avenue, Magoula, Greece, 19600, Email: johndrikos@yahoo.com

\begin{abstract}
Exomphalos is a rare congenital disorder demonstrated by failure of convergence mesoderm segments. Exomphalos is associated with congenital malformations and chromosomal abnormalities of autosomal or sex chromosomes and abnormalities with increased incidence in various systems such as renal and cardiovascular. The morbidity and mortality can be minimized by recognition of specific abnormalities associated with exomphalos development, the corresponding management and treatment strategies.
\end{abstract}

Conclusion: Exomphalos and umbilical hernias' may be associated with chromosomal abnormalities in autosomal and sex chromosomes and are related with genetic syndromes such as paternal uniparental disomy (UPD), Pallister-Killian (PKS) and Beckwith-Wiedemann syndrome. Keywords: Exomphalos; Umbicinal hernia; Chromosomal abnormalities; genetic syndromes; Abnormal karyotype

\section{Introduction}

Exomphalos separated in major and minor and could be associated with limb abnormalities, renal defects or caudal midline syndromes. Even though cardiac and renal defects are associated with the occurrence of exomphalos the prevalence is not yet associated with specific chromosomal abnormalities. Exomphalos may be associated with chromosomal abnormalities of both autosomal and sex chromosomes and other syndromes such paternal uni parental disomy (UPD), Pallister Killian (PKS) syndrome Beckwith-Wiedemann syndrome and feto placental chromosomal abnormalities (CMP). At this mini review study we will analyze the combination of exomphalos and umbicinal hernia with specific chromosomal abnormalities and genetic loci associated with the syndromes development.

\section{Umbicinal Hernia and Chromosomal Abnormalities of Autosomal Chromosomes}

Umbicinal hernia and exophalos are rare congenital conditions with an incidence of 2-3 cases per 10,000 newborns and are associated with chromosomal abnormalities in foetus and placenta [1,2]. The risk of umbilical hernia and exomphalos varies according to maternal age, gestational age, type of birth and genetic disorders $[3,4]$.
Trisomes 13 and 18 are the most common chromosomal abnormalities associated with the occurrence of umbilical hernia. Snijders et al. [3] determined the appearance of omphalocele in $22.5 \%$ of foetuses with trisomy $18,9.1 \%$ of foetuses with trisomy $13,12.5 \%$ of foetuses with other triploid chromosomal abnormalities while $0,45 \%$ of embryos had no chromosomal defects. According to literature the risk factors such as Trisomes 18 or 13 in foetuses with omphalocele is 340 times higher comparing with embryos with no exomphalos during $11^{\text {th }}$ to $14^{\text {th }}$ weeks of gestational age $[5,6]$.

Chen et al. [7] in a study of 89 cases of trisomies 18 revealed 12 cases with omphalocele (13.48\%) estimated male to female ratio of 2:1 [7]. Blazer et al studied 18 foetuses with omphalocele and diagnosed 11 cases $(61.1 \%)$ with chromosomal abnormalities, most cases related to trisomy 18, 21 and one case with fetal karyotype 45 X [6,7].

Calzolari et al. [1,2] analyzed 160 embryos and found 94 cases of umbilical hernia (58.8\%) with concomitant chromosomal abnormalities. In 60 cases revealed trisomies 18, 23 or 13, four cases with trisomy 21 and seven with other chromosomal abnormalities [1,2]. 
Gilbert \& Nicolaides [8] studied of 35 foetuses with omphalocele found that 19 had a chromosomal abnormality, 17 of them trisomy 18 and one karyotype $47 \mathrm{XXY}$ [8] while Brant berg in a study of 90 prenatally diagnosed omphalocele revealed 44 cases with chromosomal abnormalities most of them with trisomy 18, 13 and $21[4,8]$. Chromosomal abnormalities were found in majority of foetuses with central and epigastria omphalocele. On the other hand, Van de Geijn analyzed 22 foetuses with omphalocele and found 10 cases with autosomal chromosomal abnormalities, six with trisomies 18 and one with trisomy 13 [8,9].

Hughes et al. [10] studied 30 foetuses with omphalocele and found 13 cases who had chromosomal abnormalities. Most of the foetuses had trisomy 18, trisomy 13, two had a trisomy 21 and one Turner syndrome while Hwang \& Kousseff [11] in a study of 93 cases of umbilical hernia found in 37 cases with chromosomal abnormalities, including trisomy 19, 18, 11, 21 and trisomy 13. Nicolaides et al. [6] in a study of 116 foetal of omphalocele revealed 42 cases $(36.2 \%)$ of identified autosomal chromosomal abnormalities. Most of examined foetuses had trisomy 18, six had trisomy 13 [12].

Additionally, Eydoux et al. [13] in the one study of 46 embryos with omphalocele found that 12 cases $(26.1 \%)$ had chromosomal abnormalities and seven trisomy 18, trisomy 13 while Hsu et al. [14] studied 24 neonates with omphalocele and reveal six cases (25\%) with chromosomal abnormalities such as trisomy 18 and 13 [14].

Even if several studies revealed the correlation between umbilical hernia and trisomy 21; Torfs et al. [15] found only one case of trisomy 21 among 2979 newborns with omphalocele and concluded that trisomy 21 is not predispose of increased risk for umbilical hernia. Mastroiacovo et al. [16] revealed seven cases of trisomy 21 among 8560 cases of umbilical hernia. At this study the ratio was $1 / 1200$ which was significantly higher than $1 / 425,000$ of general population, suggesting that trisomy 21 increases the risk of umbilical hernia in fetus.

\section{Umbicinal Hernia and Sex Chromosomal Abnormalities}

Besides autosomal chromosome abnormalities exomphalos and umbicinal hernia can also be associated with chromosomal abnormalities of sex chromosomes such as monosomy $45 \mathrm{X}$ and trisomies $47 \mathrm{XXY}$ or $47 \mathrm{XXX}$ [17-19]. In prenatal screening is important besides abnormalities of autosomal chromosomes to identify chromosomal abnormalities of sex chromosomes as possible key factors of umbilical hernia development.

Saller et al. [17] reported the presence of monosomy $45 \mathrm{X}$ in a fetus with omphalocele while Govaerts et al. [18] identified a case of umbilical hernia in fetus with monosome $45 \mathrm{X}$ and polyhydramnion by ultrasound analysis during gestational age of 22 weeks. Goldstein \& Drugan [19] suggested that umbilical hernia in patients with Turner syndrome may be due to expression of some localized genes of X chromosome in early pregnancy. Several reports suggested that chromosomal abnormalities are more common in combination with omphalocele $[20,21]$ while the cysts of umbilical cord increase risk of aneuploidy occurrence, mainly of trisomy 18 in fetuses with omphalocele [21]. Cysts umbilical related omphalocele usually are pseudo cysts and allantoid vesicles [21].

\section{Syndrome Pallister-Killian (PKS) and Umbicinal Hernia}

Pallister-Killian (PKS) Syndrome is a malformation characterized by mosaicism and tetrasomia of $12 p$ genetic region. The PKS has the clinical features of local alopecia, severe mental retardation, seizures and frequent occurrence of diaphragmatic hernia while in some cases it may be associated with omphalocele. Tejada et al. [22] have reported a case of PKS with ultrasonographic features such as polyhydramnion, umbilical hernia and short length diagnosed with tetrasomia of $12 p$ confirmed in cell cultures of skin fibroblasts.

\section{Paternal Uniparental Disomy (UPD) of Chromosome 14 and Umbicinal Hernia}

Paternal uniparental disomy (UPD) has been reported to be associated with multiple abnormalities such as thoracic hypoplasia, ribs abnormalities, laryngomalacia, hypertrophic cardiomyopathy and mental retardation [23]. Papenhausen et al. [24], Cotter et al. [25] and Kurosawa et al. [26] reported the correlation of umbilical hernia with occurrence of UPD of chromosome 14. Towner et al suggested that prenatal diagnosis of abdominal defect associated with increased nuchal translucency or skeletal abnormalities and coexistent of UPD of chromosome 14 [27].

Several abnormal characteristics are associated with UPD on different chromosomes. For example, genetic mapping on chromosome 11 and paternal UPD connected to Beckwith Wiedemann syndrome [28,29]. UPD of chromosome 15 has also been associated with the syndromes Prader Willi and Angelman [30] as well as the UPD of chromosome 16 may also associate with abnormal phenotypes [31,32].

\section{Micro duplication of Genetic Region 15q11}

According to literature referred a case report of a foetus with exomphalos, increased nuchal translucency and normal karyotype. The ultrasound analysis revealed exomphalos with micrognathia and tetralogy of Fallout. Although the karyotype was normal molecular karyotype revealed micro duplication of $408 \mathrm{~kb}$ in chromosomal region of 15q11.2.

\section{Beckwith-Wiedemann Syndrome (BWS) and Exomphalos}

BWS caused by impairments and deficiencies occurred in the chromosomal region of $11 \mathrm{p} 15$ [33-35]. This genetic region comprises the genes involved in the cell cycle, development and tumour suppression. The chromosomal location of $11 \mathrm{p} 15$ is organized into two subareas comprising the genes IGF2 and H19 and another centromeric region includes genes CDKN1C (Kinase 
Inhibitor 1C), KCNQ1 (subfamily $\mathrm{Q}$, potassium voltage-gated channels) and KCNQ10T1 [34,35].

Mutations in CDKN1C gene (known as p57Kip2) demonstrated at $5 \%$ of patients with BWS [36]. Patients with mutations CDKN1C gene have a typical phenotype of BWS, with a very high frequency of exomphalos. The appearance of exomphalos associated quite strongly with the syndrome as $65 \%$ of patients with BWS may appear exomphalos [35,36].

Exomphalos occurrence is more frequent in patients with mutations in the genes KCNQ10T1 and CDKN1C. If methylation status of KCNQ10T1 and H19 genes is normal then sequencing analysis of CDKN1C is important especially in patients with family history of exomphalos [35,36].

\section{Fetoplacental Chromosomal Abnormalities (CMP) and Exomphalos Development}

The effects of chromosomal abnormalities in placental and foetus (CPM) are under investigation due to assess the participation of these genetic elements in exomphalos development [37]. CPM aberrations associated with growth retardation, and foetal death. The fetoplacental chromosomal abnormalities may lead to emergence of a different number of chromosomes of placenta and the foetus even if the karyotype is normal. These foetuses may reveal normal growth [38] or intrauterine growth restriction outcome that may result in intrauterine foetal death [39]. Drikos et al studied case of an infant diagnosed prenatally with exomphalos with intestinal contents from the $14^{\text {th }}$ week of gestational age. Prenatal diagnosis by choral villi sample detected pseudomosaicism of placenta (mos45X/46XY), while amniocentesis on the $19^{\text {th }}$ week of pregnancy revealed normal karyotype. This is the first reported case of placental pseudo-mosaicism (mos45X/46XY) combined with exomphalos [38].

Trisomy 2 of the placenta associated with growth retardation and abnormal clinical characteristics at birth, while the CPM on the sex chromosomes does not usually have any adverse effect on embryo development [39]. The pseudo-mosaicism of placenta may also be associated with the occurrence of umbilical hernia and various phenotypic abnormalities. In a clinical case showed non mosaic trisomy 22 in the chorionic villus, mosaic trisomy 22 in amniocytes and normal karyotype of lymphocytes showed abnormal foetal characteristics of reminiscent Goldenhar syndrome. The foetal mosaicism appears to be the likely explanation for Goldenhar syndrome [39,40].

\section{Conclusion}

Exomphalos and umbicinal hernia can quite often associate with disorders of the gastrointestinal and central nervous system seems to be predominated such as in cases of BeckwithWiedemann and abnormal karyotype syndromes.

Exomphalos may be associated with limb abnormalities or caudal midline syndromes. Although cardiac and renal abnormalities seem to be associated with the occurrence of exomphalos the prevalence is not apparently associated with chromosomal abnormalities. Such disorders may be associated with chromosomal defects at autosomal and sex chromosomes and other syndromes such as paternal uniparental disomy (UPD), Pallister-Killian (PKS) and Beckwith-Wiedemann syndromes. The determination of the associated malformations can lead to conscious prenatal counselling. This provides parents reliable and clear information's in order to determine the continuation of pregnancy.

\section{Compliance with Ethical Standards}

Funding: This mini review has been written without support of any fund.

\section{Disclosure of Potential Conflicts of Interest}

The author declares have no conflict of interest.

\section{References}

1. Calzolari E, Volpato S, Bianchi F (1993) Omphalocele and gastroschisis: a collaborative study of five Italian congenital malformation registries. Teratology 47(1): 47-55.

2. Calzolari E, Bianchi F, Dolk H, Milan M (1995) Omphalocele and gastroschisis in Europe: a survey of 3 million births 1980- 1990. EUROCAT Working Group. Am J Med Genet 58(2): 187-194.

3. Snijders RJM, Sebire NJ, Souka A, Santiago C, Nicolaides KH (1995) Fetal exomphalos and chromosomal defects: relationship to maternal age and gestation. Ultrasound Obstet Gynecol 6(4): 250-255.

4. Brantberg A, Blaas H GK, Haugen SE, Eik Nes SH (2005) Characteristics and outcome of 90 cases of fetal omphalocele. Ultrasound Obstet Gynecol 26(5): 527-537.

5. Snijders RJM, Brizot ML, Faria M, Nicolaides KH (1995) Fetal exomphalos at 11 to 14 weeks of gestation. J Ultrasound Med 14(8): 569-574.

6. Blazer S, Zimmer EZ, Gover A, Bronshtein M (2004) Fetal omphalocele detected early in pregnancy: associated anomalies and outcomes. Radiology 232(1): 191-195.

7. Chen CP (2005) Omphalocele and congenital diaphragmatic hernia associated with fetal trisomy 18. Prenat Diagn 25(5): 421-423.

8. Gilbert WM, Nicolaides KH (1987) Fetal omphalocele: associated malformations and chromosomal defects. Obstet Gynecol 70(4): 633635.

9. van de Geijn EJ, van Vugt JM, Sollie JE, van Geijn HP (1991) Ultrasonographic diagnosis and perinatal management of fetal abdominal wall defects. Fetal Diagn Ther 6(1-2): 2-10.

10. Hughes MD, Nyberg DA, Mack LA, Pretorius DH (1989) Fetal omphalocele: prenatal US detection of concurrent anomalies and other predictors of outcome. Radiology 173(2): 371-376.

11. Hwang PJ, Kousseff BG (2004) Omphalocele and gastroschisis: an 18year review study. Genet Med 6(4): 232-236.

12. Nicolaides KH, Snijders RJ, Cheng HH, Gosden C (1992) Fetal gastrointestinal and abdominal wall defects: associated malformations and chromosomal abnormalities. Fetal Diagn Ther 7(2): 102-115.

13. Eydoux P, Choiset A, Le Porrier N (1989) Chromosomal prenatal diagnosis: study of 936 cases of intrauterine abnormalities after ultrasound assessment. Prenat Diagn 9(4): 255-269.

14. Hsu CC, Lin SP, Chen CH (2002) Omphalocele and gastroschisis in Taiwan. Eur J Pediatr 161(10): 552-555. 
15. Torfs CP, Honor LH, Curry CJR (1997) Is there an association of Down syndrome and omphalocele? Am J Med Genet 73(4): 400-403.

16. Mastroiacovo P, Robert E, Kallen B (1999) Is there an association of Down syndrome and omphalocele? Am J Med Genet 82(5): 443.

17. Saller DN, Dailey JV, Doyle DL, Carr SR, Canick JA (1993) Turner syndrome associated with an omphalocele. Prenat Diagn 13(5): 424426.

18. Govaerts LC, Bongers MY, Lammens MM, Tuerlings JH, van de Kaa CA (1997) Monosomy X and omphalocele. Prenat Diagn 17(3): 282.

19. Goldstein I, Drugan A (2006) Cystic hygroma and omphalocele at 11 weeks in a fetus with monosomy X. Prenat Diagn 26(4): 381-382.

20. Nyberg DA, Fitzsimmons J, Mack LA (1989) Chromosomal abnormalities in fetuses with omphalocele, Significance of omphalocele contents. J Ultrasound Med 8(6): 299-308.

21. Chen CP, Jan SW, Liu FF (1995) Prenatal diagnosis of omphalocele associated with umbilical cord cyst. Acta Obstet Gynecol Scand 74(10): 832-835.

22. Tejada MI, Uribarren A, Briones P, Vilaseca MA (1992) A further prenatal diagnosis of mosaic tetrasomy $12 \mathrm{p}$ (Pallister- Killian syndrome). Prenat Diagn 12(6): 529-534.

23. Kotzot D, Utermann G (2005) Uniparental disomy (UPD) other than 15: phenotypes and bibliography updated. Am J Med Genet 136(3): 287 305 .

24. Papenhausen PR, Mueller OT, Johnson VP, Sutcliffe M, Diamond TM, et al. (1995) Uniparental isodisomy of chromosome 14 in two cases: an abnormal child and a normal adult. Am J Med Genet 59(3): 271-275.

25. Cotter PD, Kaffe S, McCurdy LD, Jhaveri M, Willner JP, et al. (1997) Paternal uniparental disomy for chromosome 14: a case report and review. Am J Med Genet 70(1): 74-79.

26. Kurosawa K, Sasaki H, Sato Y (2002) Paternal UPD 14 is responsible for a distinctive malformation complex. Am J Med Genet 110(3): 268-272.

27. Towner D, Yang SP, Shaffer LG (2001) Prenatal ultrasound findings in a foetus with paternal uniparental disomy 14q12-qter. Ultrasound Obstet Gynecol 18(3): 268-271.

28. Slatter R, Elliot M, Welham K, Carrera M, Schonreld P, et al. (1994) Mosaic uniparental disomy in Beckwith \pm Wiedmann syndrome. J Med Genet 31(10): 749-753.

29. Catchpoole D, Lam W, Valler D, Temple K, Joyce J, et al. (1997) Epigenetic modi®cation and uniparental inheritance of H19 in Beckwith \pm Wiedemann syndrome. J Med Genet 34(5): 353-359.
30. Ledbetter D, Engel E (1995) Uniparental disomy in humans: development of an imprinting map and its implications for prenatal diagnosis. Hum Mol Genet 4: 1757-1764.

31. Wolstenholme J (1996) Conned placental mosaicism for trisomies 2, $3,7,8,9,16$ and 22: their incidence, likely origins and mechanisms for cell lineage compartmentalization. Prenat Diagn 16(6): 511-524.

32. Tantravahi U, Matsumoto C, Delach J, Craffey A, Sweltzer J, et al. (1996) Trisomy 16 mosaicism in amniotic fluid cell cultures. Prenat Diagn 16(8): 749-754.

33. Tonni G, Bellotti M, Palmisan M, Alesi V, Bertoli M, et al. (2015) 408 kb $15 q 11.2$ microduplication by array comparative genomic hybridization in a fetus presenting with exomphalos, micrognathia, tetralogy of Fallot and normal karyotype: A genetic counseling dilemma in paternal carrier status. Congenital Anomalies 55(1): 65-70.

34. Maher ER, Brueton LA, Bowdin SC, Luharia A, Cooper W, et al. (2003) Beckwith-Wiedemann syndrome and assisted reproduction technology (ART). J Med Genet 40(1): 62-64.

35. Reik W, Walter J (2001) Genomic imprinting: parental influence on the genome. Nat Rev Genet 2(1): 21-32.

36. Lam WW, Hatada I, Ohishi S, Mukai T, Joyce JA, et al. (1999) Analysis of germline CDKN1C (p57KIP2) mutations in familial and sporadic Beckwith-Wiedemann syndrome (BWS) provides a novel genotypephenotype correlation. J Med Genet 36(7): 518-523.

37. Hansen W, Bernard L, Langlois S, Rao K, Cheicher N, et al. (1997) Maternal uniparental disomy of chromosome 2 and conned placental mosaicism for trisomy 2 in a fetus with intrauterine growth restriction, hypospadias, and oligohydramnios. Prenat Diagn 17(5): 443-450.

38. Drikos I, Mougiou V, Ragou E, Iakovidoy N Briana D, Boutsikou T, et al. (2016) Mocaicism of placenta and exomphalos at fullterm infant. $6^{\text {th }}$ National Neonatal Congress, Athens, Greece.

39. Grati R (2014) Chromosomal Mosaicism in Human Feto-Placental Development: Implications for Prenatal Diagnosis. J Clin Med 3(3): 809-837.

40. Malvestiti F, de Toffol S, Grimi B, Chinetti S, Marcato L, et al. (2014) De novo small supernumerary marker chromosomes detected on 143,000 consecutive prenatal diagnoses: Chromosomal distribution; frequencies and characterization combining molecular-cytogenetics approaches. Prenat Diagn 34(5): 460-468.

\section{Your next submission with Juniper Publishers will reach you the below assets}

- Quality Editorial service

- Swift Peer Review

- Reprints availability

- E-prints Service

- Manuscript Podcast for convenient understanding

- Global attainment for your research

- Manuscript accessibility in different formats

( Pdf, E-pub, Full Text, Audio)

- Unceasing customer service

Track the below URL for one-step submission https://juniperpublishers.com/online-submission.php 